\title{
TNFAIP8 as a predictor of metastasis and a novel prognostic biomarker in patients with epithelial ovarian cancer
}

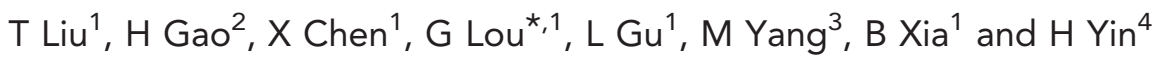 \\ ${ }^{1}$ Department of Gynecology, The Third Affiliated Hospital, Harbin Medical University, Harbin, China; ${ }^{2}$ Gastroenterologic Surgery, \\ The Third Affiliated Hospital, Harbin Medical University, Harbin, China; ${ }^{3}$ Medical Oncology, The Third Affiliated Hospital, Harbin \\ Medical University, Harbin, China and ${ }^{4}$ Department of Gynecology, Mudanjiang Tumor Hospital, Mudanjiang, China
}

Background: Tumour necrosis factor- $\alpha$-induced protein 8 (TNFAIP8) has been recently documented in various malignancies, but its role in epithelial ovarian cancer (EOC) remains unknown.

Methods: Tumour necrosis factor- $\alpha$-induced protein 8 expression was determined by real-time reverse transcription PCR and western blot analysis. Tumour tissues, consisting of serous, mucinous, endometrioid and clear cell histotypes, from 202 EOC patients (International Federation of Gynecologists and Obstetricians I-IV) who underwent primary cytoreduction were collected. Then,

we examined the immunohistochemical expression of TNFAIP8 and evaluated its clinical significances.

Results: Tumour necrosis factor- $\alpha$-induced protein 8 overexpression was significantly associated with high histologic grade $(P=0.005)$, large residual tumour size $(P=0.014)$, recurrence $(P=0.024)$ and response to chemotherapy $(P<0.001)$. Multivariate analysis showed that TNFAIP8 overexpression was independently correlated with the presence of lymph node (odds ratio (OR): 4.129; 95\% confidence interval $(\mathrm{Cl})$ : 1.491-11.435; $P=0.006$ ) and intraperitoneal metastasis (OR: 2.209; 95\% Cl: 1.174-4.156; $P=0.014)$. Moreover, results revealed that the status of TNFAIP8 expression was an independently prognostic factor for both cancer-specific survival (hazard ratio (HR): 1.852; 95\% Cl: 1.322-2.594; $P<0.001$ ) and disease-free survival (HR: $1.724 ; 95 \% \mathrm{Cl}$ : 1.235-2.407; $P=0.001$ ) in patients with EOC.

Conclusion: The present data provide evidence that TNFAIP8 predicts EOC metastasis and poor survival, highlighting its potential function as a therapeutic target for EOCs.

Epithelial ovarian carcinoma (EOC) is the most lethal gynaecologic malignancy (Siegel et al, 2012). Despite advances in surgery and new chemotherapy regimens over the last few decades, the reported 5-year survival rate for patients with EOC ranges from 25 to $30 \%$ or even less (Jemal et al, 2009; Annunziata et al, 2010). However, predictions for the patients' prognosis can be variable and inaccurate. The identification of a new cancer biomarker, in addition to common clinicopathological risk factors to select patients with good or bad outcome, will assist the follow-up management of EOC after surgery. Thus, novel prognostic and predictive markers are necessary to improve the assessment of patient outcome and to guide more targeted and individualised therapeutic decisions.

Tumour necrosis factor- $\alpha$-induced protein 8 (TNFAIP8) family, a new subfamily of death effector domain that contains proteins, consists of TNFAIP8, TIPE1, TIPE2 and TIPE3 (Freundt et al, 2008; Sun et al, 2008). Among them, TNFAIP8 (also known as SCC-S2, GG2-1 and MDC-3.13), the first identified and most investigated member, is a $21 \mathrm{kDa}$ cytosolic TNF- $\alpha$-inducible antiapoptotic and oncogenic molecule (Kumar et al, 2000, 2004). 
Tumour necrosis factor- $\alpha$-induced protein 8 was originally identified based on the comparison of a primary human head and neck squamous cell carcinoma cell line with its matched metastatic cell line established from the recurrent tumour after radiation therapy (Patel et al, 1997). Tumour necrosis factor- $\alpha$ induced protein 8 was discovered to express in various human cancer cell lines, with higher levels in K562, MOLT4, A549 and SKOV-3 and lower levels in SW480 (Kumar et al, 2000). Overexpression of TNFAIP8 in cancer cells is induced by TNF- $\alpha$ and by the activation of NF- $\kappa \mathrm{B}$ in various cells (Horrevoets et al, 1999; Kumar et al, 2000; You et al, 2001; Zhang et al, 2004), which enhance cell survival and proliferation by reducing apoptosis through the inhibition of the apoptotic protein caspase- 8 and caspase-3 activity (Kumar et al, 2000; You et al, 2001; Zhang et al, 2004, 2006; Laliberté et al, 2010). Collectively, the above functional studies suggest that TNFAIP8 may have a crucial role in tumour cell proliferation, migration, invasion and metastasis.

With regard to the possible role of TNFAIP8 in tumorigenesis and its progression, TNFAIP8 overexpression has frequently occurred in several types of cancer tissues and has exhibited clinical relevance (Kumar et al, 2004; Dong et al, 2010; Hadisaputri et al, 2012; Liu et al, 2012; Miao et al, 2012; Zhang et al, 2012, 2013; Shi et al, 2013). As of this writing, no studies on TNFAIP8 in primary EOC tissues have been conducted. Therefore, in this study, we evaluated TNFAIP8 expression in EOC and its clinical significances following the guideline for REMARK (McSane et al, 2005). The data showed the crucial role of TNFAIP8 as a prognostic and metastatic marker as well as a novel potential therapeutic target in EOC.

\section{MATERIALS AND METHODS}

Patients and clinical tissue samples. Archived formalin-fixed, paraffin-embedded specimens used for immunohistochemistry (IHC) were obtained from 202 patients with EOC and 30 patients with normal ovaries who were surgically treated in The Affiliated Tumor Hospital of Harbin Medical University from January 2004 to December 2006. The matching primary lesion, metastatic lymph node, peritoneum and omentum were available for 20 of the primary EOCs. In addition, fresh tissues from 30 patients, including tumour tissues $(n=20)$ and normal tissues $(n=10)$, were collected and stored at $-80^{\circ} \mathrm{C}$ immediately after resection to extract protein and RNA. Patients with normal ovaries underwent hysterectomy with oophorectomy for benign uterine disease. All of the patients with EOC underwent primary cytoreduction followed by standard platinum-based combination chemotherapy (Morgan et al, 2009). For early-stage patients, adequate surgery staging including para-aortic and pelvic lymph node dissection was indicated. Patients with tumour nodules outside the pelvis equal or less than $2 \mathrm{~cm}$ also had pelvic and para-aortic lymph node dissection (Fleming et al, 2009). For advanced-stage patients, suspicious and/or enlarged nodes should be ablated if possible. None of the patients received chemotherapy, radiotherapy or immunotherapy before the surgery.

The clinicopathological characteristics of EOCs are described in Table 1. Median age of the EOC patients was 54, ranging from 25 to 80 (years), and mean age was $54.23 \pm 10.513$ (years \pm s.d.). Histological typing was classified according to World Health Organization classification standards (Tavassoeli and Devilee, 2003). The grading and staging of tumours were performed according to the International Federation of Gynecologists and Obstetricians (FIGO) staging system (Benedet et al, 2000). Optimal cytoreduction was defined according to the Gynecologic Oncology Group. The largest residual tumour nodule measuring $1 \mathrm{~cm}$ or less was determined by the operating surgeon
(Ozols et al, 2003). This study was approved by the Institute Research Medical Ethics Committee of Harbin Medical University. All of the patients gave their informed consent.

Platinum sensitivity was defined as a complete response/partial response (PR) to primary platinum chemotherapy with no evidence of progression at 6 months. Platinum resistance was defined as a complete response/PR to primary platinum chemotherapy with progression within 6 months of completing therapy or with less than a PR to initial chemotherapy. Platinum refractoriness was defined as progressive disease/stable disease on primary platinum chemotherapy.

Follow-up evaluation. Examinations performed during the follow-up period included a pelvic MRI, a colour Doppler ultrasound of the liver and kidney, X-rays and serum levels of CA-125 according to the National Comprehensive Cancer Network criteria (Morgan et al, 2009). (every 3 months for 2 years; 6-month intervals for the next 3 years; and after 5 years, every 12 months for life). Cancer-specific survival (CSS) was defined as the period from the date of surgery until death or to the time of the most recent follow-up. Patients who died of other disease were excluded. Disease-free survival (DFS) was defined as the period from the date of surgery to recurrence. All EOC patients were followed up until death or the cut-off date of December 302012.

RNA preparation and reverse transcription. Total RNA was extracted from fresh frozen samples according to the protocol of RNAsimple Total RNA Kit (DP419, TIANGEN, Beijing, China) after ensuring that tumour contained more than $75 \%$ tumour cells and approval by pathologists in the pathology department. RNA quality and concentration were measured using a NanoDrop 2000 spectrophotometer (Thermo, Wilmington, DE, USA). Reverse transcriptional RNA was synthesised from $2.0 \mu \mathrm{g}$ total RNA in a $14.5 \mu$ reaction mixture using $2 \times$ Power Taq PCR MasterMix kit (PR1702, BioTeke, Beijing, China) following the manufacturer's instructions. Total RNA was reverse-transcribed with $1 \mu \mathrm{l}$ of Super M-MLV Reverse Transcriptase (PR6502, BioTeke) in a reaction container $\left(25^{\circ} \mathrm{C}\right.$ for $10 \mathrm{~min}, 42^{\circ} \mathrm{C}$ for $50 \mathrm{~min}$ and $95^{\circ} \mathrm{C}$ for $5 \mathrm{~min}$ ).

Real-time quantitative reverse transcriptase-PCR (RT-PCR). Real-time quantitative RT-PCR was performed using the Exicycler 96 real-time RT-PCR system (A-2060, BIONEER, Daejeon, Korea) and SYBR Green mastermix (SY1020, Solarbio, Beijing, China). The primers to TNFAIP8 were designed as follows: forward, 5'-TGAAGATGGAGCACTGCTGA-3'; reverse, 5'-GGTCTGTTA CCCGTTAGGAAG- $3^{\prime}$. $\quad \beta$-Actin was applied as the internal reference, its primers were as follows: forward, $5^{\prime}$-CTTAGTTGCG TTACACCCTTTCTTG-3'; reverse, 5' -CTGTCACCTTCACCGTT CCAGTTT- $3^{\prime}$. Amplification was performed under the following conditions: $95^{\circ} \mathrm{C}$ for $10 \mathrm{~min}$, followed by 40 cycles of $95^{\circ} \mathrm{C}$ for $10 \mathrm{~s}$, $60{ }^{\circ} \mathrm{C}$ for $20 \mathrm{~s}$ and $72{ }^{\circ} \mathrm{C}$ for $30 \mathrm{~s}$. Experiments were performed in triplicate in the same reaction. The results of the real-time quantitative RT-PCR experiments were calculated using the $2^{-\Delta \Delta \mathrm{C}(\mathrm{t})}$ method (Livak and Schmittgen, 2001).

Western blot analysis. Frozen tissue samples were homogenised in RIPA buffer consisting of $1 \%$ protease inhibitor mixture. The mixture was centrifuged at $12000 \mathrm{~g}$ for $15 \mathrm{~min}$ at $4{ }^{\circ} \mathrm{C}$ and the supernatant was obtained. Total proteins were quantified using the Bradford method (Thermo Scientific, Waltham, MA, USA). Briefly, $30 \mu \mathrm{g}$ of a protein extract was separated by $12 \%$ SDS polyacrylamide gel electrophoresis and transferred onto PVDF film (Millipore Company, Billerica, MA, USA). The membranes were blocked by $2 \%$ (bovine serum albumin) BSA at $37^{\circ} \mathrm{C}$ for $1 \mathrm{~h}$ and incubated overnight at $4{ }^{\circ} \mathrm{C}$. After a standard washing, the film was incubated with horseradish peroxidase-labeled secondary antibody for $1 \mathrm{~h}$ at room temperature and washed again. The blots were stained using a SuperSignal kit (Pierce, Rockford, IL, USA) and imaged by a charge-coupled camera LAS4000 (Fujifilm, Tokyo, Japan). 
A polyclonal rabbit anti-TNFAIP8 (ab64988, Abcam, Cambridge, MA, USA) was used for TNFAIP8 detection (1:500 diluted). $\beta$-Actin, a loading control, was detected using a polyclonal antibody (sc-130301, Santa Cruz Biotechnology, Santa Cruz, CA, USA). The experiment was repeated in triplicate.

Immunohistochemistry. Immunohistochemistry staining for TNFAIP8 was performed using the Two-Step IHC Detection Reagent (PV-6001) kit (Zhong Shan Golden Bridge Biological Technology Inc., Beijing, China) according to the manufacturer's instructions. Paraffin-embedded tissue blocks of the ovarian specimen were cut in a microtome to the desired thickness ( $\sim 4 \mu \mathrm{m}$ is ideal for IHC) and stained with $\mathrm{H} \& \mathrm{E}$ for tumour confirmation. In brief, tissue sections were deparaffinized in xylene and rehydrated in a series of graded alcohol using standard procedures. The sections were then immersed in 3\% hydrogen peroxide for $10 \mathrm{~min}$ to remove endogenous peroxidase. Antigen retrieval was performed using a pressure cooker with $10 \mathrm{mmoll}^{-1}$ citrate buffer ( $\mathrm{pH}$ 6.0) for $3 \mathrm{~min}$ to enhance immunoreactivity. The slides were subsequently incubated with a rabbit polyclonal antibody against TNFAIP8 (1:100 dilution; ab64988, Abcam) overnight at $4{ }^{\circ} \mathrm{C}$. After washing with phosphate-buffered saline, the rabbit secondary antibody (Zhong Shan Golden Bridge Biological Technology Inc., Beijing, China) was applied and incubated for $20 \mathrm{~min}$ at room temperature. Colour was developed using 3,3'-diaminobenzidine tetrahydrochloride (Dako, Hamburg, Germany). The slides were counterstained with Meyer's hematoxylin and dehydrated in ethanol. Finally, the slides were mounted and coverslipped with Resina. The negative control slides were stained with rabbit serum instead of primary antibodies. Nonsmall-cell lung cancer (NSCLC) with a positive expression of TNFAIP8 was considered as the positive control.

All the tissue sections were analysed by two independent pathologists experienced in evaluating IHC, and who were blinded to the clinicopathological data. The cytoplasmic staining results were scored based on the following criteria: (a) percentage of immunoreactive cells: 0 (0\%), 1 (0-10\%), 2 (11-50\%), 3 (51-70\%), $4(\geqslant 71 \%)$; and (b) staining intensity: 0 (negative staining), 1 (weak staining), 2 (moderate staining), 3 (intense staining). The final score for TNFAIP8 expression was the sum of the score for the percentage of positive cells and the intensity score that ranged from 0 to 7 (Soumaoro et al, 2004). In the statistical analysis, a final staining score less than 4 was defined as low expression, and a score equal or more than 4 as high expression. Any score discrepancies were reviewed by the original two pathologists and a senior pathologist until a consensus was reached.

Statistical analysis. All of the analyses were performed using SPSS 13.0 for Windows (SPSS, Chicago, IL, USA). For continuous variables, student's $t$-test was performed. The $\chi^{2}$ test was used to analyse the differences of categorical variables. Survival curves were plotted by using the Kaplan-Meier method and compared using the log-rank test. The Cox proportional hazard model was used for the multivariate analysis of the independent prognostic factors for CSS and DFS. Univariate and multivariate logistic regressions with covariate adjustment were used to assess the association between TNFAIP8 overexpression and EOC metastasis. Two-sided $P<0.05$ was considered as statistically significant.

\section{RESULTS}

Tumour necrosis factor- $\alpha$-induced protein $8 \mathrm{mRNA}$ and protein expression in ovarian cancer tissues. The analyses of quantitative real-time RT-PCR and western blot were used to further confirm mRNA and protein levels. The mean expression value of TNFAIP8 mRNA in cancer tissues $(6.9985 \pm 2.876$, normalised by $\beta$-actin gene expression), was significantly higher than the value
$(1.0090 \pm 0.13674)$ in normal ovarian tissues $(P<0.001$, Student's $t$-test). There was a 6.9 -fold difference between tumours and normal tissues (Figure 1A).

The difference in TNFAIP8 expression between tumours and normal tissues reflected at protein level was investigated using Western blot. TNFAIP8 was detected as a $\sim 21-\mathrm{kDa}$ band (Figure 1B). Expression of TNFAIP8 protein was elevated in samples of EOC tissues $(n=20)$ compared with that present in samples of normal ovaries $(n=10)$ (Figures 1C, $P<0.001$, Student's $t$-test).

Association between TNFAIP8 expression and clinicopathologic characteristics in EOCs. Overexpressed TNFAIP8 was detected in 116 samples (57.4\%), whereas negative or weak TNFAIP8 immunoreactivity was observed in normal ovarian tissues. TNFAIP8 was clearly localised in the cytoplasmic compartment of the tumour cells (Figure 2A). Geographic differences were also observed in TNFAIP8 cytoplasmic staining (Figure 2B), which was more intense in the invasive foci than in the in primary foci among the same patients (20 patients). TNFAIP8 overexpression in ascites was also observed (Supplementary Figure 1).

As shown in Table 1, elevated TNFAIP8 expression was significantly associated with high histologic grade $(P=0.037)$, large residual tumour size $(P=0.014)$, recurrence $(P=0.024)$, response to chemotherapy $(P<0.001)$ and the presence of intraperitoneal metastasis $(P=0.011)$ and lymph node metastasis $(P=0.008)$. However, no strong association was observed between TNFAIP8 and age, FIGO stage, histological type, ascites and serum CA-125 level $(P>0.05)$. The associations between the mean scores of TNFAIP8 and clinicopathological variables are shown in Supplementary Table 1.

Predictive significance of TNFAIP8 expression in EOCs with peritoneum and lymph node metastases. We conducted separate univariate analyses of clinicopathologic variables for the metastasis of the peritoneum and lymph nodes. Following clinical advice, the FIGO stage was excluded in this study. The presence of intraperitoneal metastasis was positively associated with the presence of ascites $(P=0.009)$ and large residual tumour size $(P=0.047)$. Moreover, a direct correlation between the metastasis of lymph node and high histologic grade $(P=0.043)$ and serum CA-125 level $(P=0.030)$ was established.

A multivariate logistic regression analysis was performed to evaluate the independently predictive significance of TNFAIP8 overexpression for intraperitoneal metastasis (Table 2). The result showed that the presence of ascites $(P=0.003$, odds ratio $(\mathrm{OR})$ : 2.833, 95\% confidence interval (CI): $1.427-5.624)$ and TNFAIP8 overexpression $(P=0.014$, OR: $2.209,95 \%$ CI: 1.174-4.156) were independently associated with intraperitoneal metastasis. As described above, the multivariate logistic regression analysis demonstrated that TNFAIP8 overexpression was significantly associated with the presence of lymph node metastasis ( $P=0.006$, OR: 4.129, 95\% CI: 1.491-11.435) (Table 2).

Prognostic significance of TNFAIP8 expression in EOC patients. Univariate and multivariate analyses were conducted to determine the predictors for CSS and DFS (Table 3). In the univariate analysis, results revealed that advanced FIGO stage, high histologic grade, large residual tumour size and TNFAIP8 overexpression were significant indicators of poor survival. However, age, histological type, ascites and serum CA-125 level did not affect CSS and DFS $(P>0.05)$. For CSS prediction, advanced FIGO stage $(P<0.001$, hazard ratio $(\mathrm{HR})=6.783,95 \% \mathrm{CI}: 2.496-18.434)$, large residual tumour size $(P=0.001, \mathrm{HR}=1.995,95 \% \mathrm{CI}: 1.240-2.972)$, and TNFAIP8 overexpression $(P<0.001, \mathrm{HR}=1.852,95 \% \mathrm{CI}$ : $1.322-2.594)$ were independent factors confirmed by multivariate analysis. The multivariate analysis also showed that advanced FIGO stage $(P<0.001, \quad \mathrm{HR}=7.213,95 \%$ CI: $2.652-19.618)$, 


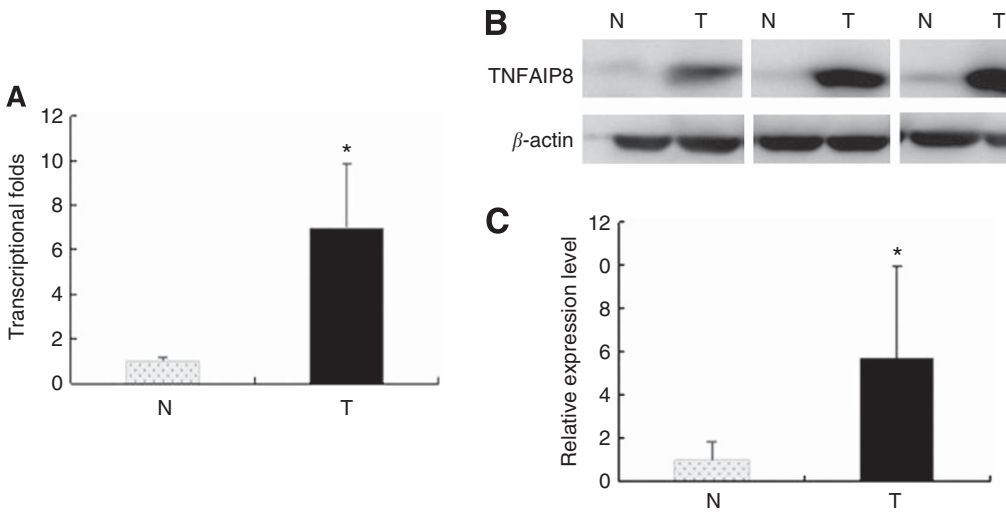

Figure 1. Tumour necrosis factor- $\alpha$-induced protein 8 elevated expression in clinical EOC tissues. (A) Real-time PCR assay of TNFAIP8. Histogram of TNFAIP8 mRNA expression in normal ovaries $(N, n=10)$ and in EOC tissues $(T, n=20)$. The levels of $\beta$-actin were used as an internal control, and the TNFAIP8 mRNA expression was calculated by $2^{-\Delta \Delta C t}$ method. The relative TNFAIP8 mRNA expression was elevated in EOCs compared with normal ovaries. The data are presented as mean \pm s.d., ${ }^{\star} P<0.05$. Normalisation: TNFAIP8/actin was first calculated and then normal pooled and normalised to 1.00. (B) Representative western blot analysis of TNFAIP8 expression in ovarian tissues. Protein samples obtained from normal ovaries $(N, n=10)$ and EOCs $(T, n=20)$ were analysed using SDS-PAGE followed by immunoblotting with antibody against TNFAIP8. The levels of $\beta$-actin were used as an internal control. (C) Histogram of pooled data from normal ovaries $(N, n=10)$ and EOCs $(T, n=20)$. The expression of TNFAIP8 protein was significantly increased in EOCs compared with normal ovaries. The data are presented as mean \pm s.d., ${ }^{*} P<0.05$. Normalisation: TNFAIP8/actin was first calculated and then normal pooled and normalised to 1.00 .

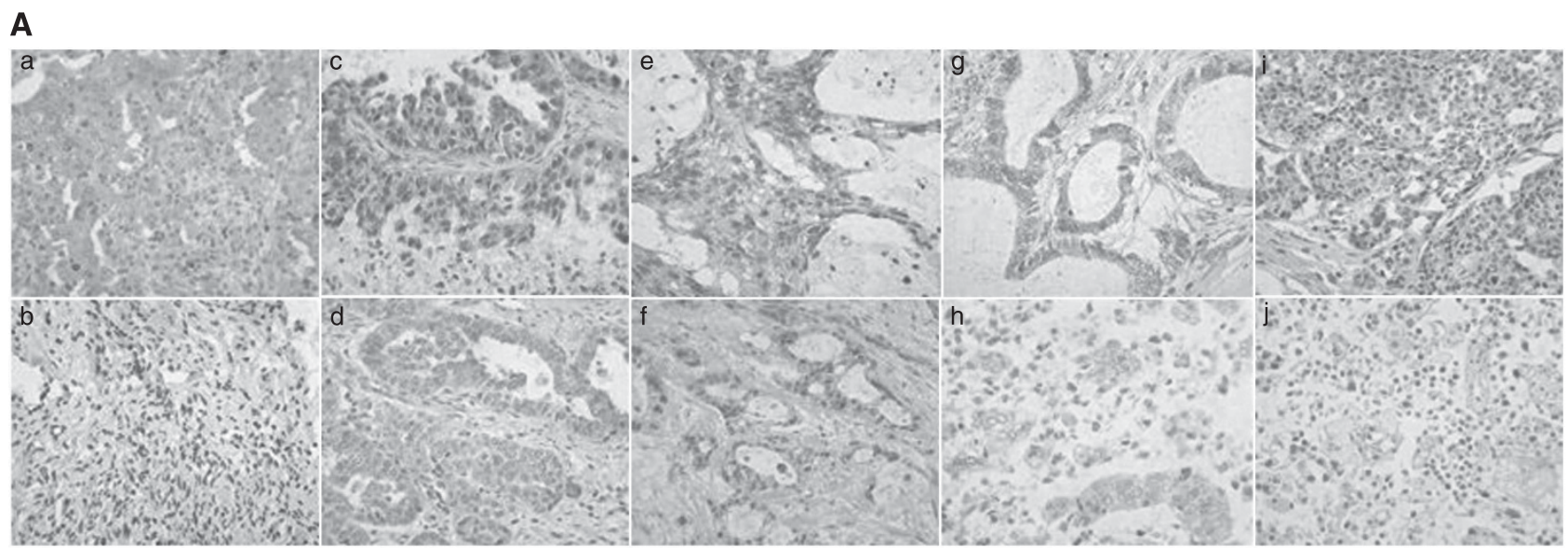

\section{B}

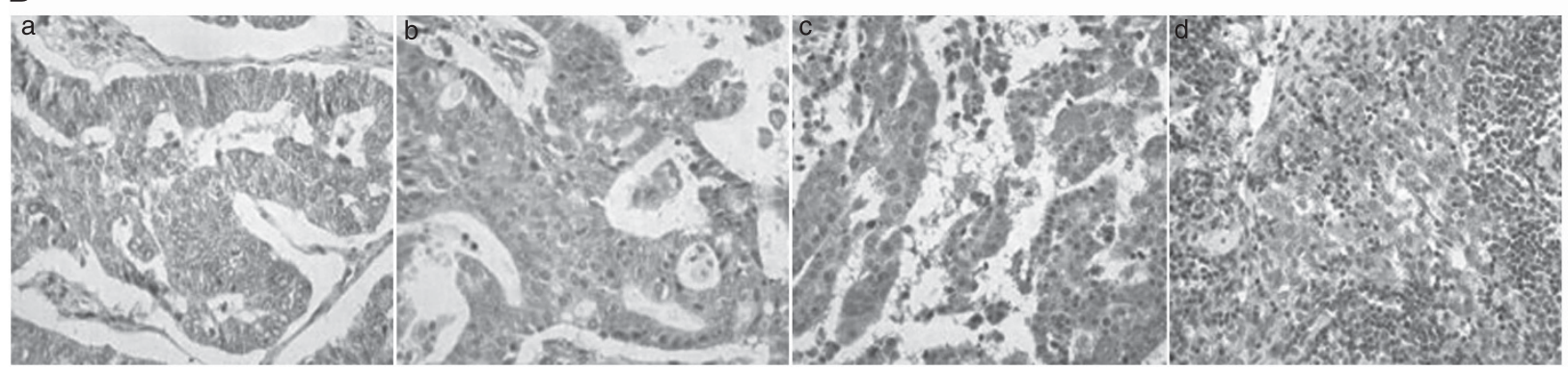

Figure 2. Representative photomicrographs of TNFAIP8 immunohistochemical staining. (A) Tumour necrosis factor- $\alpha$-induced protein 8 expression in ovarian tissues. (a) Positive control in lung cancer. (b) Negative staining in normal ovary. (c) High expression in serous histotypes. (d) Low expression in serous histotypes. (e) High expression in mucinous histotypes. (f) Low expression in mucinous histotypes. (g) High expression in endometrioid histotypes. (h) Low expression in endometrioid histotypes. (i) High expression in clear cell histotypes. (j) Low expression in clear cell histotypes ( $\times 400$ original magnification). (B) TNFAIP8 expression in primary and metastatic lesions from the same patient. (a) Primary lesion. (b) Metastatic omentum. (c) Metastatic peritoneum. (d) Metastatic lymph node ( $\times 400$ original magnification).

high histologic grade $(P=0.027, \quad \mathrm{HR}=1.446, \quad 95 \% \quad \mathrm{CI}$ : $1.043-2.005)$, large residual tumour size $(P=0.004, \mathrm{HR}=1.777$, 95\% CI: $1.197-2.637)$ and TNFAIP8 overexpression $(P=0.001$, $\mathrm{HR}=1.724,95 \% \quad \mathrm{CI}: 1.235-2.407)$ were also independent predictors for DFS.
The 5-year CSS and DFS rates were $22.7 \%$ and $16.6 \%$, respectively, in patients with a high level of TNFAIP8 expression, compared with the $51.2(P<0.001)$ and $40.1 \%(P<0.001)$ in their counterparts. To eliminate the effect of FIGO stage on prognosis, we performed a stage-stratified analysis of all patients according to 
Table 1. Association between TNFAIP8 expression levels and clinicopathological characteristics of EOC

TNFAIP8 expression

\begin{tabular}{|l|l|c|c|c|}
\hline Variables & NO. =202 & $\begin{array}{c}\text { Low (\%) } \\
\text { (no.=86) }\end{array}$ & $\begin{array}{c}\text { High (\%) } \\
(\text { no.=116) }\end{array}$ & P-value \\
\hline
\end{tabular}

Age (years)

\begin{tabular}{|l|c|c|c|c|}
\hline$\leqslant 54$ & 97 & $45(46.4)$ & $52(53.6)$ & 0.292 \\
$>54$ & 105 & $41(39.1)$ & $64(60.9)$ & \\
\hline
\end{tabular}

\section{FIGO stage}

\begin{tabular}{|l|c|r|r|r|}
\hline$I$ & 15 & $9(60.0)$ & $6(40.0)$ & 0.068 \\
IIII-IV & 26 & $15(57.7)$ & $11(42.3)$ & \\
\hline
\end{tabular}

Histologic grade

\begin{tabular}{|l|c|c|c|c|}
\hline G1/G2 & 76 & $42(55.3)$ & $34(44.7)$ & 0.005 \\
G3 & 126 & $44(34.9)$ & $82(65.1)$ & \\
\hline
\end{tabular}

\section{Histological type}

\begin{tabular}{|l|c|r|r|r|}
\hline Serous & 128 & $55(43.0)$ & $73(57.0)$ & 0.138 \\
Mucinous & 29 & $9(31.0)$ & $20(69.0)$ & \\
Endometrioid & 33 & $19(57.6)$ & $14(42.4)$ & \\
Clear cell & 12 & $3(25.0)$ & $9(75.0)$ & \\
\hline
\end{tabular}

\section{Residual tumour size}

\begin{tabular}{l|c|c|c|c|}
\hline $\begin{array}{l}\leqslant 1 \mathrm{~cm} \\
>1 \mathrm{~cm}\end{array}$ & $\begin{array}{c}168 \\
34\end{array}$ & $\begin{array}{r}78(46.4) \\
8(23.6)\end{array}$ & $\begin{array}{l}90(53.6) \\
26(76.4)\end{array}$ & 0.014 \\
\hline Ascites & \\
\hline $\begin{array}{l}\leqslant \\
>100 \mathrm{ml}\end{array}$ & 54 & $20(37.0)$ & $34(63.0)$ & 0.336 \\
\hline & 148 & $66(44.6)$ & $82(55.4)$ & \\
\hline
\end{tabular}

\section{Serum CA-125 level}

\begin{tabular}{|l|c|c|c|c|}
\hline$\leqslant 35 \mathrm{U} \mathrm{ml}^{-1}$ & 65 & $25(38.5)$ & $40(61.5)$ & 0.415 \\
$>35 \mathrm{U} \mathrm{ml}^{-1}$ & 137 & $61(44.5)$ & $76(55.5)$ & \\
\hline
\end{tabular}

\section{Recurrence}

\begin{tabular}{|l|c|c|c|c|}
\hline Yes & 95 & $33(34.7)$ & $62(65.3)$ & 0.024 \\
No & 107 & $53(49.5)$ & $54(50.5)$ & \\
\hline
\end{tabular}

\section{Response to chemotherapy}

\begin{tabular}{|l|c|r|l|l|}
\hline Platinum sensitive & 134 & $73(54.5)$ & $61(45.5)$ & $<0.001$ \\
Platinum resistant & 46 & $10(21.7)$ & $36(78.3)$ & \\
Platinum refractory & 22 & $3(13.6)$ & $19(86.4)$ & \\
\hline
\end{tabular}

\section{Intraperitoneal metastasis}

\begin{tabular}{|l|c|c|c|c|}
\hline Yes & 137 & $50(36.5)$ & $87(63.5)$ & 0.011 \\
No & 65 & $36(55.4)$ & $29(44.6)$ & \\
\hline
\end{tabular}

Lymph node metastasis no. $=81$

\begin{tabular}{|l|l|l|l|l|}
\hline Yes & 47 & $15(31.9)$ & $32(68.1)$ & 0.008 \\
No & 34 & $21(63.6)$ & $13(36.4)$ & \\
\hline
\end{tabular}

Abbreviations: $\mathrm{FIGO}=$ International Federation of Gynecology and Obstetrics; TNFAIP8 = tumour necrosis factor- $\alpha$-induced protein 8 ; no. =number of patients; $\%=$ percentage of patients. Note: 81 patients underwent para-aortic and pelvic lymph node dissection.

the level of TNFAIP8 expression and found that TNFAIP8 overexpression highly affected CSS and DFS in patients with advanced FIGO stage (III-IV) $(P<0.001$ for both). The survival
Table 2. The relationships of TNFAIP8 expression with intraperitoneal and lymph node metastasis by ultivaritae analysis

\begin{tabular}{|c|c|c|c|c|c|}
\hline Variable & B & S.E. & $P$-value & OR & $95 \% \mathrm{Cl}$ \\
\hline \multicolumn{6}{|c|}{ Intraperitoneal metastasis $($ no. $=202$ ) } \\
\hline \multicolumn{6}{|c|}{ Residual tumour size } \\
\hline$\leqslant 1 \mathrm{~cm}$ vs $>1 \mathrm{~cm}$ & 0.929 & 0.500 & 0.063 & 2.533 & $0.950-6.753$ \\
\hline \multicolumn{6}{|l|}{ Ascites } \\
\hline$\leqslant 100 \mathrm{ml} v s>100 \mathrm{ml}$ & 1.041 & 0.350 & 0.003 & 2.833 & $1.427-5.624$ \\
\hline
\end{tabular}

\begin{tabular}{|c|c|c|c|c|c|}
\hline Low vs high & 0.792 & 0.323 & 0.014 & 2.209 & $1.174-4.156$ \\
\hline \multicolumn{6}{|l|}{ Age (years) } \\
\hline$\leqslant 54$ vs $>54$ & -0.172 & 0.318 & 0.588 & 0.842 & $0.451-1.570$ \\
\hline
\end{tabular}

Lymph node metastasis (no. $=81$ )

\section{Histologic grade}

\begin{tabular}{|l|l|l|l|l|l|}
\hline G1/G2 vs G3 & 0.923 & 0.510 & 0.070 & 2.518 & $0.926-6.845$ \\
\hline
\end{tabular}

\section{Serum CA-125 level}

\begin{tabular}{|l|l|l|l|l|l|}
\hline $\begin{array}{l}\leqslant 35 \mathrm{U} \mathrm{ml}^{-1} \mathrm{vs} \\
>35 \mathrm{U} \mathrm{ml}^{-1}\end{array}$ & 1.079 & 0.558 & 0.053 & 2.943 & $0.986-8.787$ \\
\hline
\end{tabular}

\section{TNFAIP8 expression}

\begin{tabular}{|l|l|l|l|l|l|}
\hline Low vs high & 1.418 & 0.520 & 0.006 & 4.129 & $1.491-11.435$ \\
\hline Age (years) & 0.061 & 0.508 & 0.905 & 1.062 & $0.392-2.878$ \\
\hline$\leqslant 54$ vs $>54$ &
\end{tabular}

Abbreviations: $\mathrm{B}$ and S.E. $=$ the parameter estimator of association coefficient and its standard error; $\mathrm{Cl}=$ confidence interval; $\mathrm{OR}=$ odds ratio; TNFAIP8 = tumour necrosis factor-

$\alpha$-induced protein 8 ; no. $=$ number of patients

curves for the EOC patients in the two groups stratified by FIGO stage are illustrated in Figure 3.

\section{DISCUSSION}

To the best of our knowledge, the present study is the first to argue that unlike in normal ovarian tissues, TNFAIP8 expression is upregulated at both mRNA and protein levels in EOCs. High expression level of TNFAIP8 and its cytoplasmic localisation are significantly associated with high histologic grade, large residual tumour size, recurrence, response to chemotherapy, and, most importantly, the presence of intraperitoneal and lymph node metastases. The preferential expression of TNFAIP8 in EOCs also serves as an independent prognostic factor for poor CSS and DFS, particularly in advanced EOCs (FIGO stage III-IV).

The increasing incidence, delayed detection and poor prognosis of this disease underline the need to search for new strategies for diagnosis, follow-up and treatment. In line with the possible role of TNFAIP8 in human tumorigenesis, previous studies have proven that TNFAIP8 overexpression was detected in several human malignant tumours at both mRNA and protein levels (Kumar et al, 2004; Dong et al, 2010; Hadisaputri et al, 2012; Liu et al, 2012; Miao et al, 2012). Positive correlations of TNFAIP8 with histologic grade, residual tumour size, recurrence and metastases of the 
Table 3. Univariate and multivariate analysis for cancer-specific survival and disease-free urvivlal.

\begin{tabular}{|c|c|c|c|c|c|c|}
\hline \multirow[b]{3}{*}{ Variable } & \multicolumn{3}{|c|}{ Cancer-specific survival } & \multicolumn{3}{|c|}{ Disease-free survival } \\
\hline & \multirow{2}{*}{$\begin{array}{c}\text { Univariate } \\
\boldsymbol{P} \text {-value }\end{array}$} & \multicolumn{2}{|c|}{ Multivariate } & \multirow{2}{*}{$\begin{array}{c}\text { Univariate } \\
P \text {-value } \\
\end{array}$} & \multicolumn{2}{|c|}{ Multivariate } \\
\hline & & $\mathrm{HR}(95 \% \mathrm{Cl})$ & $\boldsymbol{P}$-value & & HR $(95 \% \mathrm{Cl})$ & $P$-value \\
\hline \multicolumn{7}{|l|}{ Age (years) } \\
\hline $\begin{array}{l}\leqslant 54 \\
>54\end{array}$ & 0.063 & - & - & 0.218 & - & - \\
\hline \multicolumn{7}{|l|}{ FIGO stage } \\
\hline $\begin{array}{l}\text { I } \\
\text { II } \\
\text { III-IV }\end{array}$ & $<0.001$ & $\begin{array}{c}1.000 \\
2.518(0.819-7.743) \\
6.783(2.496-18.434)\end{array}$ & $\begin{array}{c}<0.001 \\
0.107 \\
<0.001\end{array}$ & $<0.001$ & $\begin{array}{c}1.000 \\
2.659(0.865-8.175) \\
7.213(2.652-19.618)\end{array}$ & $\begin{array}{c}<0.001 \\
0.088 \\
<0.001\end{array}$ \\
\hline \multicolumn{7}{|c|}{ Histologic grade } \\
\hline $\begin{array}{l}\mathrm{G} 1 / \mathrm{G} 2 \\
\mathrm{G} 3\end{array}$ & 0.040 & $\begin{array}{c}1.000 \\
1.362(0.980-1.892)\end{array}$ & 0.066 & 0.040 & $\begin{array}{c}1.000 \\
1.446(1.043-2.005)\end{array}$ & 0.027 \\
\hline \multicolumn{7}{|c|}{ Histological type } \\
\hline $\begin{array}{l}\text { Serous } \\
\text { Mucinous } \\
\text { Endometrioid } \\
\text { Clear cell }\end{array}$ & 0.082 & - & - & 0.052 & - & - \\
\hline \multicolumn{7}{|c|}{ Residual tumour size } \\
\hline $\begin{array}{l}\leqslant 1 \mathrm{~cm} \\
>1 \mathrm{~cm}\end{array}$ & $<0.001$ & $\begin{array}{c}1.000 \\
1.995(1.340-2.972)\end{array}$ & 0.001 & $<0.001$ & $\begin{array}{c}1.000 \\
1.777(1.197-2.637)\end{array}$ & 0.004 \\
\hline \multicolumn{7}{|l|}{ Ascites } \\
\hline $\begin{array}{l}\leqslant 100 \mathrm{ml} \\
>100 \mathrm{ml}\end{array}$ & 0.464 & - & - & 0.799 & - & - \\
\hline \multicolumn{7}{|c|}{ Serum CA-125 level } \\
\hline $\begin{array}{l}\leqslant 35 \mathrm{U} \mathrm{ml}^{-1} \\
>35 \mathrm{U} \mathrm{ml}^{-1}\end{array}$ & 0.216 & - & - & 0.189 & - & - \\
\hline \multicolumn{7}{|c|}{ TNFAIP8 expression } \\
\hline $\begin{array}{l}\text { Low } \\
\text { High }\end{array}$ & $<0.001$ & $\begin{array}{c}1.000 \\
1.852(1.322-2.594)\end{array}$ & $<0.001$ & $<0.001$ & $\begin{array}{c}1.000 \\
1.724(1.235-2.407)\end{array}$ & 0.001 \\
\hline
\end{tabular}

peritoneum and lymph node have been demonstrated in the current study. The elevated TNFAIP8 expression that correlates with tumour stage and lymph node metastasis was observed in pancreatic cancer, colon cancer, NSCLC and oesophageal squamous cell cancer (Dong et al, 2010; Hadisaputri et al, 2012; Liu et al, 2012; Miao et al, 2012). In NSCLC and oesophageal squamous cell cancer, TNFAIP8 was proven to be a poor prognostic marker, although it was not an independent factor (Dong et al, 2010; Hadisaputri et al, 2012). Zhang et al, (2013) argued that nuclear TNFAIP8 overexpression is an independent predictor of recurrent prostate cancer. Furthermore, functional variants in TNFAIP8 were believed to result in tumour progression and poor outcome of cervical cancer by inhibiting the response of tumour cells to platinum drugs, particularly cisplatin and nedaplatin (Shi et al, 2013). Zhang et al (2012) also observed that the polymorphism of TNFAIP8 was correlated with nonHodgkin's lymphoma. Collectively, these data suggest that TNFAIP8 has a significant role in the oncogenesis and progression of human malignancies. Though no association between FIGO stage and TNFAIP8 expression (low and high) was observed in this study, we found that the mean scores of TNFAIP8 correlated with FIGO stage. Therefore, further confirming this conclusion in patients with EOC is of paramount importance.

Clinically, the presence of EOC metastasis is not always easy to assess in daily practice, which effectively affects the survival outcome (Eisenkop et al, 1998; Chi et al, 2004, 2006). The elucidation of molecules and signalling pathways that drive metastasis in EOC is likely to provide new avenues for the early identification and therapeutic intervention of aggressive EOC. A multivariate logistic regression analysis was proposed to further characterise this clinical implication of TNFAIP8 in EOCs. Interestingly, we clarified that TNFAIP8 may be useful as an adjunct in the evaluation of metastases of the peritoneum and lymph node. The fact that TNFAIP8 is highly expressed in the invasive foci and the areas of primary lesion (Figure $2 \mathrm{~B}$ ) reflects its preferential expression in areas of intense tumour growth. In preliminary functional studies, overexpression of exogenous TNFAIP8 or inhibition of TNFAIP8 with antisense oligo could 

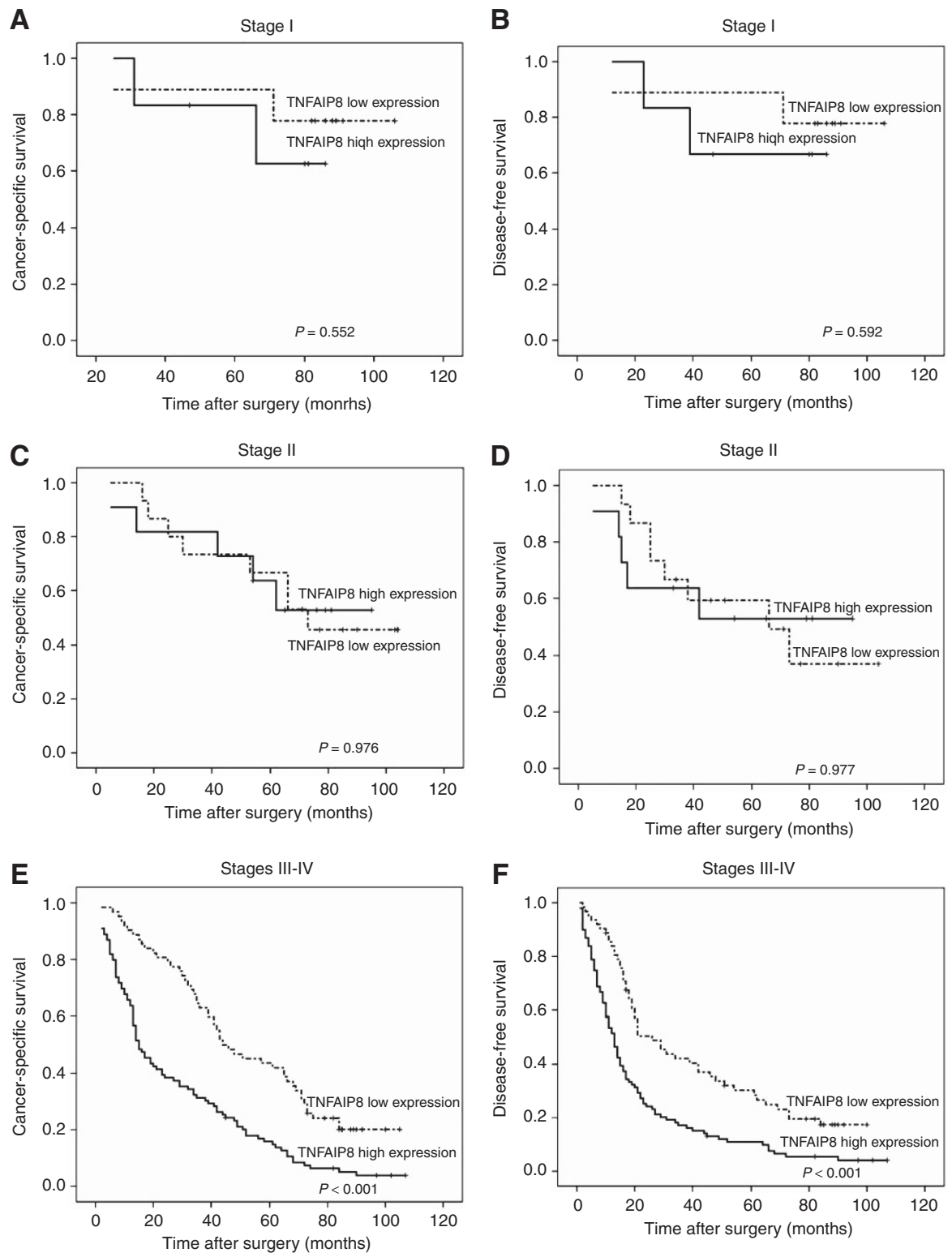

Figure 3. A stage-stratified analysis of TNFAIP8 expression in patients with EOC. Survival curves showing the correlation of TNFAIP8 with CSS and DFS in EOC patients in different FIGO stages. (A) Cancer-specific survival in FIGO stage I. (B) Disease-free survival in FIGO stage I. (C) Cancer-specific survival in FIGO stage II. (D) Disease-free survival in FIGO stage II. (E) Cancer-specific survival in FIGO stage III-IV. (F) Disease-free survival in FIGO stage III-IV.

modify the metastatic properties in MDA-MB 435 cells (Kumar et al, 2004). In addition, the depletion of TNFAIP8 expression using siRNA could simultaneously decrease the expression of fundamental elements of the extracellular matrix and VEGFR-2 in PC-3 cells (Zhang et al, 2013). Conversely, in lung cancer cells, downregulation of TNFAIP8 was believed to result in a significant inhibition of cancer cell growth and invasion, which was independent of MMPs (Dong et al, 2010). Taken together, a dramatic breakthrough has come with the identification of the aggressive and invasive effects of TNFAIP8 in tumours.

Thus far, evidence linking TNFAIP8 oncogene to the survival of several cancer types (Dong et al, 2010; Hadisaputri et al, 2012; Shi et al, 2013) without controlling the tumour stage exists. Indeed, FIGO stage in EOCs is pivotal for survival (Park et al, 2012) with that the 5-year survival rate of early-stage EOC varies from 50 to $85 \%$ (Richardson et al, 1985). By performing a stage-stratified analysis, we demonstrated that TNFAIP8 overexpression may be a prognostic indicator for advanced EOC.
In the light of the above findings, TNFAIP8 can, therefore, be considered as a novel marker of intraperitoneal and lymph node metastases and a promising therapeutic target in EOC patients. Although the results are intriguing, this investigation has limitations. The current study is a retrospective analysis with a limited number of patients. Thus, a more thorough investigation in a larger series of patients is necessary to confirm the use of this new variable. The exploration of possible mechanism of EOC metastasis caused by TNFAIP8 overexpression is ongoing in our laboratory.

\section{ACKNOWLEDGEMENTS}

This study was supported by grants from Heilongjiang Special Funds for outstanding youth (No. JC201108), Heilongjiang Province, China.

\section{CONFLICT OF INTEREST}

The authors declare no conflict of interest. 


\section{REFERENCES}

Annunziata CM, Stavnes HT, Kleinberg L, Berner A, Hernandez LF, Birrer MJ, Steinberg SM, Davidson B, Kohn EC (2010) Nuclear factor kappaB transcription factors are coexpressed and convey a poor outcome in ovarian cancer. Cancer 116: 3276-3284.

Benedet JL, Bender H, Jones 3rd H, Ngan HY, Pecorelli S (2000) FIGO staging classifications and clinical practice guidelines in the management of gynecologic cancers. FIGO Committee on Gynecologic Oncology. Int J Gynaecol Obstet 70: 209-262.

Chi DS, Eisenhauer EL, Lang J, Huh J, Haddad L, Abu-Rustum NR, Sonoda Y, Levine DA, Hensley M, Barakat RR (2006) What is the optimal goal of primary cytoreductive surgery for bulky stage IIIC epithelial ovarian carcinoma (EOC)? Gynecol Oncol 103: 559-564.

Chi DS, Franklin CC, Levine DA, Akselrod F, Sabbatini P, Jarnagin WR (2004) Improved optimal cytoreduction rates for stages IIIC and IV epithelial ovarian, fallopian tube, and primary peritoneal cancer: a change in surgical approach. Gynecol Oncol 94: 650-654.

Dong QZ, Zhao Y, Liu Y, Wang Y, Zhang PX, Jiang GY, Dong XJ, Cui QZ, Wang EH (2010) Overexpression of SCC-S2 correlates with lymph node metastasis and poor prognosis in patients with non-small-cell lung cancer. Cancer Sci 101: 1562-1569.

Eisenkop SM, Friedman RL, Wang HJ (1998) Complete cytoreductive surgery is feasible and maximizes survival in patients with advanced epithelial ovarian cancer: a prospective study. Gynecol Oncol 69: 103-108.

Fleming, Ronnett B, Seidman J, Zaino RJ, Rubin SC (2009) Epithelial Ovarian Cancer. In Principles and Practice of Gynecologic Oncology, Barakat RR, Markman M, Randall ME (eds). pp 763-835. Lippincott Willians \& Wilkins: Philadelphia, PA, USA.

Freundt EC, Bidere N, Lenardo MJ (2008) A different TIPE of immune homeostasis. Cell 133: 401-402.

Hadisaputri YE, Miyazaki T, Suzuki S, Yokobori T, Kobayashi T, Tanaka N, Inose T, Sohda M, Kuwano H (2012) TNFAIP8 overexpression: clinical relevance to esophageal squamous cell carcinoma. Ann Surg Oncol 19(Suppl 3): S589-S596.

Horrevoets AJ, Fontijn RD, van Zonneveld AJ, de Vries CJ, ten Cate JW, Pannekoek H (1999) Vascular endothelial genes that are responsive to tumor necrosis factor-alpha in vitro are expressed in atherosclerotic lesions, including inhibitor of apoptosis protein-1, stannin, and two novel genes. Blood 93: 3418-3431.

Jemal A, Siegel R, Ward E, Hao Y, Xu J, Thun MJ (2009) Cancer statistics, 2009. CA Cancer J Clin 59: 225-249.

Kumar D, Gokhale P, Broustas C, Chakravarty D, Ahmad I, Kasid U (2004) Expression of SCC-S2, an antiapoptotic molecule, correlates with enhanced proliferation and tumorigenicity of MDA-MB 435 cells. Oncogene 23: 612-616.

Kumar D, Whiteside TL, Kasid U (2000) Identification of a novel tumor necrosis factor-alpha-inducible gene, SCC-S2, containing the consensus sequence of a death effector domain of fas-associated death domain-like interleukin-1beta-converting enzyme-inhibitory protein. J Biol Chem 275: 2973-2978.

Laliberté B, Wilson AM, Nafisi H, Mao H, Zhou YY, Daigle M, Albert PR (2010) TNFAIP8: a new effector for Galpha(i) coupling to reduce cell death and induce cell transformation. J Cell Physiol 225: 865-874.

Liu K, Qin CK, Wang ZY, Liu SX, Cui XP, Zhang DY (2012) Expression of tumor necrosis factor-alpha-induced protein 8 in pancreas tissues and its correlation with epithelial growth factor receptor levels. Asian Pac J Cancer Prev 13: 847-850.

Livak KJ, Schmittgen TD (2001) Analysis of relative gene expression data using real-time quantitative PCR and the 2(-Delta Delta $\mathrm{C}(\mathrm{T})$ ) Method. Methods 25: 402-408.

McSane LM, Altman DG, Sauerbrei W, Sauerbrei SE, Gion M, Clark GM (2005) REporting recommendations for tumour MARKer prognostic studie (REMARK). Br J Cancer 93: 387-391.

Miao Z, Zhao T, Wang Z, Xu Y, Song Y, Wu J, Xu H (2012) SCC-S2 is overexpressed in colon cancers and regulates cell proliferation. Tumour Biol 33: 2099-2106.
Morgan RJ, Alvarez RD, Armstrong DK, Boston B, Burger R, Chen LM, Copeland L, Crispens MA, Fowler J, Gaffney DK, Gershenson D, Greer BE, Grigsby PW, Havrilesky LJ, Johnston C, Lancaster JM, Lele S, Markman M, Matulonis UA, O’Malley DM, Ozols RF, Penson RT, Remmenga SW, Sabbatini P, Schink J, Teng N (2009) Ovarian cancer including Fallopian tube cancer and Primary peritoneal cancer. NCCN clinical practice guidelines in oncology.

Ozols RF, Bundy BN, Greer BE, Fowler JM, Clarke-Pearson D, Burger RA, Mannel RS, DeGeest K, Hartenbach EM, Baergen R. Gynecologic Oncology Group (2003) Phase III trial of carboplatin and paclitaxel compared with cisplatin and paclitaxel in patients with optimally resected stage III ovarian cancer: a Gynecologic Oncology Group study. J Clin Oncol 21: 3194-3200.

Park HJ, Nam EJ, Rha SY, Kim S, Kim SW, Kim JW, Kim YT (2012) A new prognostic index model using meta-analysis in early-stage epithelial. Gynecol Oncol 126: 357-363.

Patel S, Wang FH, Whiteside TL, Kasid U (1997) Identification of seven differentially displayed transcripts in human primary and matched metastatic head and neck squamous cell carcinoma cell lines: implications in metastasis and/or radiation response. Oral Oncol 33: 197-203.

Richardson GS, Scully RE, Nikrui N, Nelson Jr JH (1985) Common epithelial cancer of the ovary (2). N Engl J Med 312: 415-424.

Shi TY, Cheng X, Yu KD, Sun MH, Shao ZM, Wang MY, Zhu ML, He J, Li QX, Chen XJ, Zhou XY, Wu X, Wei Q (2013) Functional variants in TNFAIP8 associated with cervical cancer susceptibility and clinical outcomes. Carcinogenesis 34: 770-778.

Siegel R, Naishadham D, Jemal A (2012) Cancer statistics, 2012. CA Cancer J Clin 62: 10-29.

Soumaoro LT, Uetake H, Higuchi T, Takagi Y, Enomoto M, Sugihara K (2004) Cyclooxygenase-2 expression: a significant prognostic indicator for patients with colorectal cancer. Clin Cancer Res 10: 8465-8471.

Sun H, Gong S, Carmody RJ, Hilliard A, Li L, Sun J, Kong L, Xu L, Hilliard B, Hu S, Shen H, Yang X, Chen YH (2008) TIPE2, a negative regulator of innate and adaptive immunity that maintains immune homeostasis. Cell 133: 415-426.

Tavassoeli FA, Devilee P (2003) WHO Classification of Tumours, Pathology and Genetics: Tumours of the Breast and Female Genital Organs. IARC: Lyon, France.

You Z, Ouyang H, Lopatin D, Polver PJ, Wang CY (2001) Nuclear factor-kappa B-inducible death effector domain-containing protein suppresses tumor necrosis factor-mediated apoptosis by inhibiting caspase-8 activity. J Biol Chem 276: 26398-26404.

Zhang C, Chakravarty D, Sakabe I, Mewani RR, Boudreau HE, Kumar D, Ahmad I, Kasid UN (2006) Role of SCC-S2 in experimental metastasis and modulation of VEGFR-2, MMP-1, and MMP-9 expression. Mol Ther 13: 947-955.

Zhang C, Kallakury BV, Ross JS, Mewani RR, Sheehan CE, Sakabe I, Luta G, Kumar D, Yadavalli S, Starr J, Sreenath TL, Srivastava S, Pollard HB, Eidelman O, Srivastava M, Kasid UN (2013) The significance of TNFAIP8 in prostate cancer response to radiation and docetaxel and disease recurrence. Int J Cancer 133: 31-42.

Zhang HG, Hyde K, Page GP, Brand JP, Zhou J, Yu S, Allison DB, Hsu HC, Mountz JD (2004) Novel tumor necrosis factor alpha-regulated genes in rheumatoid arthritis. Arthritis Rheum 50: $420-431$.

Zhang Y, Wang MY, He J, Wang JC, Yang YJ, Jin L, Chen ZY, Ma XJ, Sun MH, Xia KQ, Hong XN, Wei QY, Zhou XY (2012) Tumor necrosis factor- $\alpha$ induced protein 8 polymorphism and risk of non-Hodgkin's lymphoma in a Chinese population: a case-control study. PLoS One 7: e37846.

This work is published under the standard license to publish agreement. After 12 months the work will become freely available and the license terms will switch to a Creative Commons AttributionNonCommercial-Share Alike 3.0 Unported License.

Supplementary Information accompanies this paper on British Journal of Cancer website (http://www.nature.com/bjc) 